\title{
EXPLORING AND PROVING COMPLEX COMPOUNDS IN BROTOWALI (Tinospora crispa)
}

\author{
W.T. Widodo ${ }^{1,2}$, D.J.D.H. Santjojo ${ }^{3}$, S. Widyarti ${ }^{1}$ and S.B. Sumitro, ${ }^{1,}$ \\ ${ }^{1}$ Department of Biology, Faculty of Mathematics and Natural Sciences, Brawijaya University, \\ Malang, Indonesia, 65145. \\ ${ }^{2}$ STIKes Karya Putra Bangsa, Tulungagung, Indonesia, 66291. \\ ${ }^{3}$ Department of Physics, Faculty of Mathematics and Natural Sciences, Brawijaya University, \\ Malang, Indonesia, 65145. \\ Corresponding Author: sutiman@ub.ac.id
}

\begin{abstract}
Many complex compounds play a role in the physiological process and body metabolism. It is thought that complex compounds can occur naturally in plants. This study aimed to determine the presence of complex compounds in Brotowali (Tinospora crispa). The compound content was analyzed by LCMS (Liquid Chromatography-Mass Spectrometry). Transition metal content was analyzed by XRF (X-Ray Fluorescence). FTIR (Fourier-Transform Infrared Spectroscopy) and XRD (X-Ray Diffraction) analysis confirmed the existence of complex compounds. The LCMS analysis results showed the existence of betaine, DL-Carnitine, Ferulic acid, Adenosine, Choline, and Berberine. XRF analysis showed that the brotowali samples contained various metals, including $\mathrm{Fe}, \mathrm{Cu}$, and $\mathrm{Mn}$. Predictions of complex compounds formed in Brotowali include Fe metal binds to 3 choline molecules, and Fe metal binds to 1 DL-Carnitine molecule. FTIR analysis and XRD analysis showed that the brotowali samples contained complex compounds. The analysis results indicated that the Brotowali naturally contained complex compounds.
\end{abstract}

Keywords: Bioinorganic, Brotowali, Herbs, Medicinal Plants, Transition Metal Complexes

RASĀYAN J. Chem., Vol. 14, No.4, 2021

\section{INTRODUCTION}

A complex compound or bioinorganic complex is a compound containing an ion complex. An ion complex consists of one central metal cation in the form of a transition metal or metal in the main group and binds to neutral anions or molecules called ligands. ${ }^{1}$ Many complex compounds play a role in physiological and metabolic processes in the human body, for example, acting as radical scavengers like hemoglobin and SOD (superoxide dismutase). In the hemoglobin structure, there is metal Fe as the center of the atom. ${ }^{2}$

Complex compounds are thought to form in plants naturally. They are formed from the content of compounds in plants and metals that plants absorb. One of the nutrients absorbed by plants is transition metals. Complex compounds are present in some plants. Flavonoid-Fe complexes are found in Syzygium cumini. $^{3}$ Oleuropein-Cu complex is also found in Olea europea. ${ }^{4}$

Complex compounds have several advantages compared to their single compounds. It has been shown that flavonoid complexes with transition metals have stronger radical scavenging activity than their single flavonoids. ${ }^{5}$ The mechanism of free radical scavenging from a single compound will produce new radicals because a single compound loses its electrons. ${ }^{6}$ Complex compounds only change their paramagnetic properties to be diamagnetic or vice versa, as is the nature of the transition metal, which is the central atom, ${ }^{7}$ as happened to the enzymes SOD and hemoglobin. Brotowali is a plant that is commonly found in tropical areas and is used to treat various diseases, such as diabetes, hypertension, back pain, bruises, septicemia, fever, fractures, scabies, diabetes, and hypertension. Brotowali contains many compounds, including flavonoids, terpenoids, alkaloids, lignans, nucleosides, and sterols. ${ }^{8}$ This study explored and verified complex compounds in Brotowali plants using LCMS, XRF, FTIR, and XRD analysis.

\section{EXPERIMENTAL}

Brotowali stems were cut into pieces then dried in the oven. The dried brotowali pieces were ground until smooth and then sieved with a 200 mesh sieve. A total of 100 grams of sieved powder were boiled with 1 
$\mathrm{L}$ distilled water for 30 minutes. The results of the decoction were used directly for the LCMS analysis. The solvent was removed by freeze-drying. The powder from freeze-drying was used for XRF, FTIR, and XRD analysis.

\section{LCMS Analysis}

The content of the compounds in the Brotowali sample was identified by LCMS analysis. Brotowali boiled water was filtered using a $0.22 \mu \mathrm{m}$ syringe filter and injected into the column. Analysis was performed using Thermo Scientific Dionex Ultimate 3000 RSLC with Hypersil GOLD aQ analytical column and Thermo Scientific Q Exactive Mass Spectrometer (MS). Chromatographic and MS conditions were performed according to Sukmaniningsih. ${ }^{3}$

\section{XRF Analysis}

The transition metal content in the sample was tested by XRF (PANalytical MiniPal 4). The results were analyzed using an absorption standard which resulted in a percentage (\%) ratio of metal elements to the total area of the peaks that appeared in the absorption pattern.

\section{FTIR Analysis}

The existence of the transition metal compound complexes with the active compound was tested using an FTIR spectrophotometer (Shimadzu, Japan). A total of $3 \mathrm{mg}$ of sample powder was mixed with $\mathrm{KBr}$ (5 $10 \%$ of the sample) and homogenized. The homogeneous mixture was then made with $\mathrm{KBr}$ pellets $(\mathrm{KBr}$ pills). Once formed, the $\mathrm{KBr}$ pill was ready to be analyzed using an FTIR spectrophotometer.

\section{XRD Analysis}

XRD analysis aimed to identify the presence of crystal structures in brotowali samples. Analysis used $\mathrm{X}^{\prime}$ Pert ${ }^{3} \mathrm{MRD}$. K $\alpha$ beam $(\mathrm{Cu}) 1.5406 \AA$, $40 \mathrm{kV}, 35 \mathrm{~mA}$. The scanning region $(2 \theta)$ was from $10^{\circ}$ to $65^{\circ}$.

\section{RESULTS AND DISCUSSION}

Brotowali contains many compounds. ${ }^{9}$ Some of the compounds confirmed by the LCMS analysis include Betaine, DL-Carnitine, Ferulic acid, Adenosine, Choline, and Berberine (Fig.-1). These compounds can act as free radicals. ${ }^{10-15}$

XRF results showed that Brotowali has many metal content, including transition metals (Table-1). Several transition metals played a large role in human biological processes. There were some compounds found in brotowali, including $\mathrm{Fe}(3.67 \%), \mathrm{Cu}(0.54 \%)$, and $\mathrm{Mn}(0.28 \%)$.

The characteristic of transition metals is that they have not fully filled electrons in the d subshell, so that they can form a cation and bind with other molecules. ${ }^{16}$ These transition metals can bind with compounds that have a hydroxyl group $(-\mathrm{OH})$ or a carbonyl group $(=\mathrm{O})$ to form complex compounds. Some of the predictions of complex compounds in Brotowali include Fe metal binds to 3 choline (Fig.-2a) molecules and $\mathrm{Fe}$ metal binds to 1 DL-Carnitine (Fig.-2b). Predictions of these compounds are drawn using ChemDraw Pro 8.0.

The presence of complex compounds in the Brotowali sample was proven from the results of the FITR analysis. FTIR analysis can detect functional groups through infrared absorption. ${ }^{17}$ Complex compounds have coordination bonds between transition metals and $\mathrm{O}$ atoms to form a specific group. Complex compounds of Fe metal form Fe-O groups, complex compounds of $\mathrm{Mn}$ metal form $\mathrm{Mn}-\mathrm{O}$ groups, and complex compounds of $\mathrm{Cu}$ metal form $\mathrm{Cu}-\mathrm{O}$ groups. In FTIR analysis, the $\mathrm{Fe}-\mathrm{O}$ group causes absorption at a wavelength of $625-490 \mathrm{~cm}^{-1}$, the Mn-O group causes absorption at a wavelength of $765-735 \mathrm{~cm}^{-1}$, and the $\mathrm{Cu}-\mathrm{O}$ group causes absorption at a wavelength of $875-825 \mathrm{~cm}^{-1}{ }^{18}$

The absorption appeared at $510 \mathrm{~cm}^{-1}, 600 \mathrm{~cm}^{-1}, 615 \mathrm{~cm}^{-1}, 758 \mathrm{~cm}^{-1}, 874 \mathrm{~cm}^{-1}$ in brotowali samples in the wavelength range of $1000 \mathrm{~cm}^{-1}-400 \mathrm{~cm}^{-1}$ (Fig.-3). The absorption indicated the existence of Fe complex compounds $\left(510 \mathrm{~cm}^{-1}, 600 \mathrm{~cm}^{-1}, 615 \mathrm{~cm}^{-1}\right)$, Mn complex compounds $\left(758 \mathrm{~cm}^{-1}\right)$ and $\mathrm{Cu}$ complex compounds $\left(874 \mathrm{~cm}^{-1}\right)$.

The presence of complex compounds in brotowali could also be confirmed by XRD analysis. Complex compounds have atoms arranged regularly to form a crystal structure. ${ }^{19,20}$ The crystal structure can be observed by XRD analysis. ${ }^{21}$ The sharp and narrow peaks of high intensity indicate a crystal structure. ${ }^{22}$ 


\section{RASĀYAN J. Chem.}

Vol. 14 | No. 4 |2666-2670| October- December | 2021

The diffraction peaks appeared at an angle of $2 \theta 15^{\circ}, 24^{\circ}, 30^{\circ}, 38^{\circ}$ in the brotowali sample (Fig.-4). This strengthens the evidence that in the Brotowali sample, there are complex compounds.
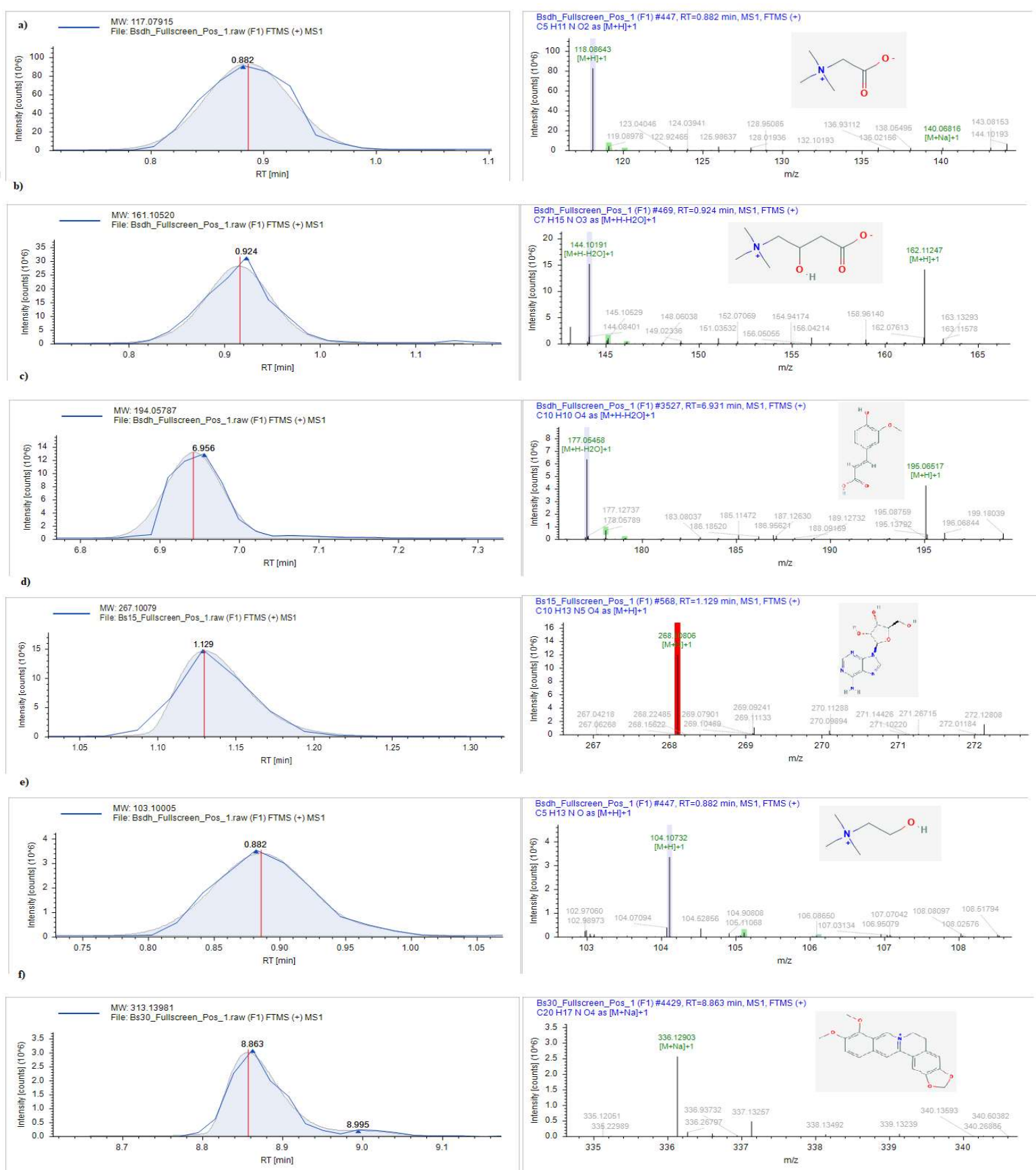

Fig.-1: LC-MS Chromatogram of (a) Betaine, (b) DL-Carnitine, (c) Ferulic Acid, (d) Adenosine, (e) Choline, and (f) Berberine in Brotowali

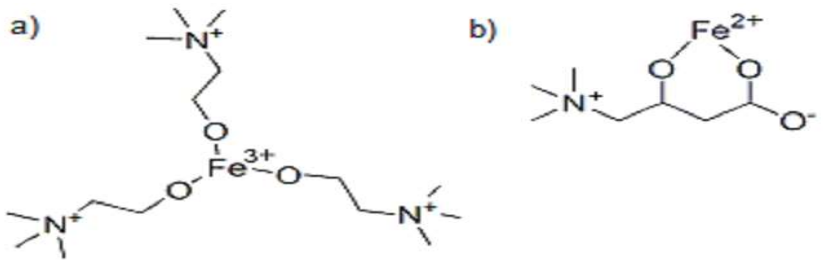

Fig.-2: Prediction Structure of 3 choline-Fe ${ }^{2+}$ and 1 DL-Carnitine-Fe ${ }^{3+}$ 
RASĀYAN J. Chem.

Vol. 14 | No. 4 |2666-2670| October- December | 2021
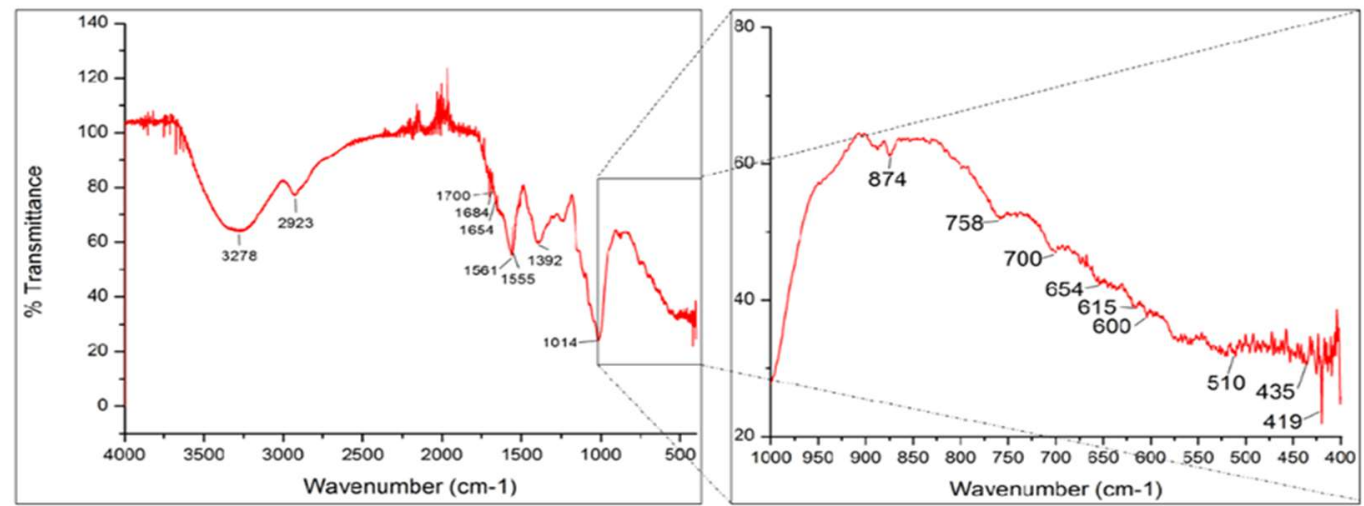

Fig.-3: FTIR Spectra of Brotowali Samples

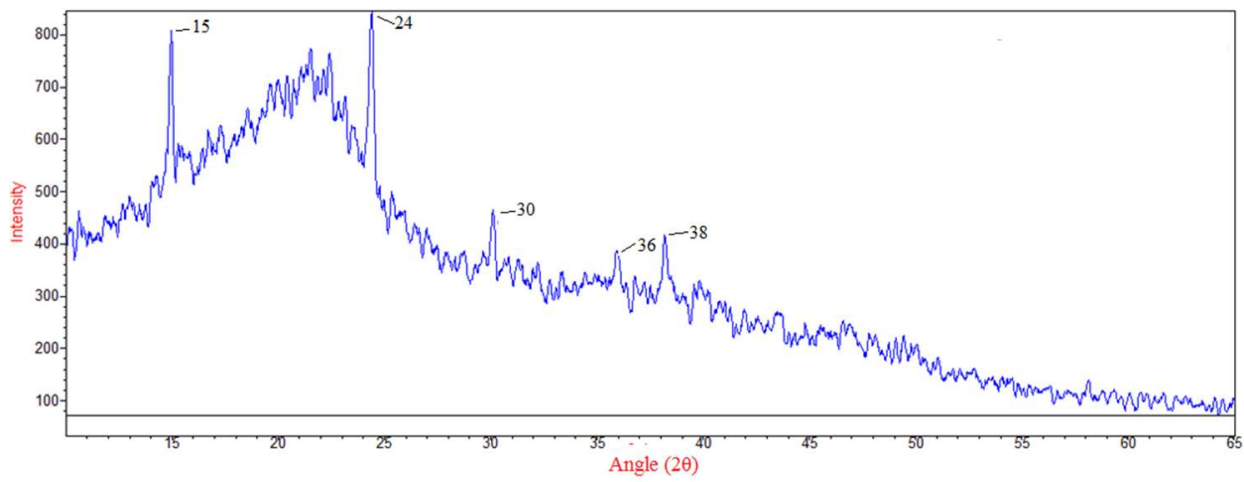

Fig.-4: XRD Results of the Brotowali Sample

In various countries, Brotowali is known to have many benefits and uses. ${ }^{8}$ One of these benefits is due to the presence of complex compounds naturally contained in Brotowali. Complex compounds have better pharmacological activity than single compounds.

There are different mechanisms between single compounds and compounds that have formed bioinorganic complexes in counteracting free radicals. When a single flavonoid reacts with a free radical, a radical flavonoid will be produced because it has donated its electrons. However, when a bioinorganic complex gives its electrons to a radical, it does not turn into a radical but only changes its magnetic properties from paramagnetic to diamagnetic or vice versa. ${ }^{3}$

\section{CONCLUSION}

Based on the LCMS and XRF analysis, Brotowali contains various compounds and transition metals, which are predicted to form complex compounds with compound contents. FTIR and XRD analysis proved that complex compounds naturally formed in brotowali.

\section{ACKNOWLEDGEMENT}

This research was funded by the Ministry of Research and Technology (KEMENRISTEKDIKTI) Indonesia through the "Penelitian Disertasi Doktor." Contract Number : 023/5P2H/LT/DRPM/2021, Date:18/032021.

\section{REFERENCES}

1. J. E. House, Inorganic Chemistry, Academic Press, Cambridge, p.601,602 (2019).

2. K.T. Patton, G.A. Thibodeau and C.P. Anthony, Anthony's Textbook of Anatomy \& Physiology, Missouri, Elsevier, p.650, 651 (2013).

3. A.A.S.A. Sukmaningsih, S. Permana, D.J.D.H. Santjojo, A.Y.P. Wardoyo and S.B. Sumitro, Rasāyan Journal of Chemistry, 11(3), 1193(2018), https://doi.org/10.31788/RJC.2018.1133047

4. C.R. Capo, J.Z. Pedersen, M. Falconi and L. Rossi, Journal of Trace Elements in Medicine and Biology, 44, 225(2017), https://doi.org/10.1016/j.jtemb.2017.08.002

5. E. Jabeen, N.K. Janjua, S. Ahmed, I. Murtaza, T. Ali and S. Hameed, Spectrochimica Acta Part A: 
RASĀYAN J. Chem. Vol. 14 | No. 4 |2666-2670| October- December | 2021

Molecular and Biomolecular Spectroscopy, 171, 432(2017), https://doi.org/10.1016/j.saa.2016.08.035

6. F. Ahmadinejad, S. Geir Moller, M. Hashemzadeh-Chaleshtori, G. Bidkhori and J. Mohammad-Saeid, Antioxidants, 6(3), 51(2017), https://doi.org/10.3390/antiox6030051

7. J.A. McMillan, Journal of Chemical Education. 38(9), 438(1961), https://doi.org/10.1021/ed038p438

8. W. Ahmad, I. Jantan and S.N.A. Bukhari, Frontiers in Pharmacology, 7, 59(2016), https://doi.org/10.3389/fphar.2016.00059

9. P. Sharma, B. P. Dwivedee, D. Bisht, A. K. Dash, and D. Kumar, Heliyon, 5(9), e02437(2019), https://doi.org/10.1016/j.heliyon.2019.e02437

10. M. Zhang, H. Zhang, H. Li, F. Lai, X. Li, Y. Tang, T. Min, and H. Wu, Journal of Agricultural and Food Chemistry, 64(42), 7921(2006), https://doi.org/10.1021/acs.jafc.6b03592

11. M. Zhou, Z. Wu, R. Liang and N. Gu, Aquaculture Research, 48(3), 1279(2017), https://doi.org/10.1111/are.12970

12. A. Amić, Z. Marković, J. M. Dimitrić Marković, D. Milenković, and V. Stepanić, Phytochemistry. 170, 112218(2020), https://doi.org/10.1016/j.phytochem.2019.112218

13. F. Valdes, N. Brown, A. Morales-Bayuelo, L. Prent-Peñaloza, and M. Gutierrez, Antioxidants, 8(10), 468(2019), https://doi.org/10.3390/antiox8100468

14. V. Pavić, D. Flačer, M. Jakovljević, M. Molnar, and S. Jokić, Plants, 8(3), 69, https://doi.org/10.3390/plants8030069

15. M. Roselli, M. M. Cavalluzzi, C. Bruno, A. Lovece, A. Carocci, C. Franchini, S. Habtemariam, and G. Lentini, Phytochemistry Letters, 18, 150(2016), https://doi.org/10.1016/j.phytol.2016.10.005

16. R. H. Crabtree, The Organometallic Chemistry of the Transition Metals: Sixth Edition, Wiley, Chichester, p.48 (2014), https://doi.org/10.1002/9781118788301

17. S.A. Khan, S.B. Khan, Khan LU, Farooq A, Akhtar K, A.M. Asiri, 2018, Fourier Transform Infrared Spectroscopy: Fundamentals and Application in Functional Groups and Nanomaterials Characterization, In: Sharma S. (eds), Handbook of Materials Characterization, Springer, pp. 317-344, https://doi.org/10.1007/978-3-319-92955-2 9

18. S. Venkateswarlu, B. Natesh Kumar, C.H. Prasad, P. Venkateswarlu and N.V.V. Jyothi. Bio- Physica B: Condensed Matter, 449, 67(2014), https://doi.org/10.1016/j.physb.2014.04.031

19. E. Semitut, V. Komarov, T. Sukhikh, E. Filatov and A. Potapov, Crystals, 6(11), 138(2016); https://doi.org/10.3390/cryst6110138

20. E Vílchez-Rodríguez, I Pérez-Toro, A Bauzá and A Matilla-Hernández, Crystals, 6(11), 139(2016), https://doi.org/10.3390/cryst6110139

21. M. Nasrollahzadeh, M. Atarod, M. Sajjadi, S.M. Sajadi, Z. Issaabadi, 2019, Plant-mediated Green Synthesis of Nanostructures: Mechanisms, Characterization, and Applications, in: M. Nasrollahzadeh, S.M. Sajadi, M. Sajjadi, Z. Issaabadi and M. Atarod (Eds.), Interface Science and Technology, Elsevier, Amsterdam, pp. 199-322, https://doi.org/10.1016/B978-0-12-813586-0.00006-7

22. I. Chi-Duran, Z. Setifi, F. Setifi, C. Jelsch, B. Morgenstern, A. Vega, F. Herrera, D.P. Singh, K. Hegetschweiler and R. Boyaala, Acta Crystallographica Section E: Crystallographic Communications, 75, 867(2019), https://doi.org/10.1107/S2056989019006959

[RJC- 6562/2021] 